\title{
Hypothalamic-Pituitary-Adrenal Axis Activity and Sleep in Posttraumatic Stress Disorder
}

\author{
Christian Otte ${ }^{1,2,3}$, Maryann Lenoci ${ }^{2}$, Thomas Metzler ${ }^{2}$, Rachel Yehuda ${ }^{4}$, Charles R Marmar ${ }^{1,2}$ and \\ Thomas C Neylan*,1,2 \\ 'Department of Psychiatry, University of California, San Francisco, CA, USA; ${ }^{2}$ Veterans Affairs Medical Center, San Francisco, CA, USA; \\ ${ }^{3}$ Department of Psychiatry and Psychotherapy, University Hospital Hamburg-Eppendorf, Germany; ${ }^{4}$ Department of Psychiatry, Mount Sinai \\ School of Medicine, New York, NY, USA
}

\begin{abstract}
Alterations of the hypothalamic-pituitary-adrenal (HPA) axis and sleep disturbances have been described separately in post-traumatic stress disorder (PTSD). It is not known if HPA alterations and sleep disturbances are associated in PTSD. This study examined sleep and HPA activity in 20 male medication-free subjects with PTSD and 16 matched healthy controls. Two nights of polysomnography were obtained and 24-h urinary cortisol was collected during day 2. Subjects self-administered a low-dose (0.5 mg) salivary dexamethasone test at home. Compared with controls, PTSD subjects had higher 24-h urinary $\mu \mathrm{g}$ cortisol/g creatinine (mean \pm SD $40 \pm 17 \mathrm{vs} 28 \pm 12$, $p=0.03$ ) but not significantly higher $24-h$ urinary cortisol (mean \pm SD $52 \pm 15 \mu \mathrm{g} /$ day vs $43 \pm 23, p=0.19$ ). PTSD subjects showed a trend towards less cortisol suppression after dexamethasone (73\% \pm 18 vs $83 \% \pm 10, p=0.06)$. In the combined sample, delta sleep was significantly and negatively correlated with 24-h urinary cortisol $(r=-0.36, p=0.04)$, and with 24-h urinary cortisol/g creatinine on a trend level $(r=-0.34, p=0.06)$. Our results suggest that increased cortisol is negatively associated with delta sleep. This may contribute to sleep abnormalities in conditions associated with elevated cortisol, possibly including PTSD. Future studies should explore the temporal relationship between HPA activity, sleep disturbances, and psychopathology after a traumatic event. Neuropsychopharmacology (2005) 30, I I73-I I80, advance online publication, I6 February 2005; doi: I 0. I038/sj.npp. I 300676
\end{abstract}

Keywords: posttraumatic stress disorder; sleep; cortisol; HPA axis; corticotropin-releasing-hormone

\section{INTRODUCTION}

Sleep disturbances are among the most common symptoms of post-traumatic stress disorder (PTSD) and are represented by nightmares (in the re-experiencing cluster) and difficulty in falling and staying asleep (in the hyperarousal cluster) as specified in DSM-IV criteria (Neylan et al, 1998; Pillar et al, 2000). Hence, it is surprising that only two studies have shown that PTSD, a putative hyperarousal disorder, is associated with decreased visually scored delta sleep (Glaubman et al, 1990; Kramer and Kinney, 1988). This contrasts with a larger number of studies of PTSD that have found no differences in visually scored delta sleep (Mellman et al, 1995a-c, 1997; Ross et al, 1994a, b; Woodward et al, 1996a-c). One possible explanation for failing to find reduced delta sleep in PTSD relates to the

\footnotetext{
*Correspondence: Dr TC Neylan, Veterans Affairs Medical Center, 4150 Clement Street (I16 P), San Francisco, CA 94121, USA, Tel: + I 415221 4810 ext. 696I, Fax: + I 4157512297 , E-mail: neylan@itsa.ucsf.edu

Received 6 May 2004; revised 14 December 2004; accepted 15 December 2004

Online publication: 17 December 2004 at http://www.acnp.org/ citations/NPP I 2 1 7040402 I 5/default.pdf
}

poor sensitivity of visual sleep staging, or sleep macroarchitecture, in quantifying delta sleep. Indeed, the only two studies that applied quantitative measures of delta sleep have found decreased delta sleep in patients with PTSD (Neylan et al, 2003; Woodward et al, 2000).

In healthy subjects, delta sleep activity peaks in the first half of the night and is temporally associated with the nadir of cortisol output (Steiger, 2002). Delta sleep is believed to be the primary marker for sleep homeostasis and the restorative function of sleep (Borbely and Achermann, 2000). Multiple studies have shown that increased hypothalamic corticotropin-releasing factor (CRF) release is associated with disturbed sleep and particularly with decreased delta sleep activity (reviewed in Neylan et al, 2003). In turn, treatment with a CRF receptor antagonist increased delta sleep in depressed patients (Held et al, 2004).

While there are consistent results of elevated CRF in the cerebrospinal fluid in PTSD patients (Baker et al, 1999; Bremner et al, 1997), studies using 24-h urinary cortisol and the dexamethasone suppression test to characterize HPA activity have reported variable results. In PTSD, 24-h urinary cortisol was increased (De Bellis et al, 1999; Lemieux and Coe, 1995; Maes et al, 1998; Pitman and Orr, 1990), unchanged (Baker et al, 1999; Rasmusson et al, 2001; 
Young and Breslau, 2004) or decreased (Thaller et al, 1999; Yehuda et al, 1995, 1990) compared to healthy controls. Also, cortisol suppression after dexamethasone was reported to be diminished (Atmaca et al, 2002; Thaller et al, 1999), unchanged (Dinan et al, 1990; Halbreich et al, 1989; Lindley et al, 2004; Lipschitz et al, 2003), or to be enhanced (Stein et al, 1997; Yehuda et al, 2002, 1993). Some of these inconsistencies might be related to differences among studies regarding the study population, age, and gender differences, use of psychotropic medication, comorbid substance abuse, and dose of dexamethasone (for reviews, see Rasmusson et al, 2003; Yehuda, 2002).

We have previously shown that PTSD subjects had a diminished adrenocorticotropin (ACTH) response and a less pronounced decrease of delta sleep to an indirect CRF challenge with metyrapone (Neylan et al, 2003). In that study, PTSD subjects had significantly less delta sleep, but no significant differences in total sleep time, sleep maintenance, REM latency, or REM density compared to control subjects. By blocking the last step of cortisol synthesis, metyrapone acutely reduces cortisol levels, attenuates cortisol-mediated feedback inhibition at the pituitary, hypothalamus, and hippocampus, while increasing the release of hypothalamic CRF. Therefore, an attenuated increase of ACTH and a diminished decrease of delta sleep after metyrapone in subjects with PTSD could be explained by chronic increased CRF activity and downregulated CRF receptors.

To extend our previous findings with metyrapone that suggested increased CRF in PTSD, in the current study we examined the relation between delta sleep and $24 \mathrm{~h}$ urinary cortisol in 20 male medication-free subjects with PTSD without any substance abuse in the last 2 years and 16 ageand sex-matched controls. Since previous literature in PTSD reported both 24-h urinary cortisol and 24-h urinary cortisol per g creatinine (Glover and Poland, 2002; Lemieux and Coe, 1995; Rasmusson et al, 2001), we examined both parameters. Subjects also self-administered a low-dose $(0.5 \mathrm{mg})$ salivary dexamethasone suppression test at home to specifically address the issue of possible enhanced negative feedback inhibition in PTSD (Yehuda, 2002).

We hypothesized that (1) there would be a negative correlation between delta sleep and 24-h urinary cortisol and 24-h urinary cortisol/g creatinine, respectively and (2) that subjects with PTSD would have less 24-h urinary cortisol, less 24-h urinary cortisol/g creatinine, and an increased negative feedback inhibition of salivary cortisol after $0.5 \mathrm{mg}$ of dexamethasone compared to controls.

\section{MATERIALS AND METHODS}

\section{Participants}

Medically healthy male subjects between 20 and 60 years were recruited from web-based and newspaper advertisement and from the San Francisco Veterans Affairs Medical Center PTSD Outpatient Program. For this study, only men were included to eliminate the possible confound of gender, which has been demonstrated both in HPA activity (Heuser et al, 1994; Otte et al, 2005; Seeman et al, 1995) and sleep (Armitage and Hoffmann, 2001). All subjects provided written informed consent. The study protocol and consent form was approved by the Committee on Human Research at the University of California, San Francisco (UCSF). In all, 20 PTSD subjects and 16 controls completed two nights of polysomnography on the General Clinical Research Center at UCSF. Subjects spent the three days on the General Clinical Research Center at UCSF. They were allowed to have one cup of coffee in the morning, but were not allowed to nap during the day.

Patients were included when they were positive for current chronic PTSD, as indexed by the Clinician Administered PTSD Scale (CAPS) criteria (Blake et al, 1995). Subjects filled out the Beck Depression Inventory (BDI) (Beck et al, 1961) and the Impact of Event ScaleRevised (IES-R) (Weiss and Marmar, 1996) each morning after the sleep recordings.

Subjects were excluded if they met the criteria for alcohol or substance abuse within the past 2 years, schizophrenia, schizoaffective disorder, bipolar disorder, and obsessive compulsive disorder as assessed by the Structured Clinical Interview for DSM-IV (SCID; First et al, 1996). Medical exclusion criteria included any history of central nervous system disease, or use of any medication affecting the brain. All subjects were free of any psychotropic medications and had not been hospitalized for at least 2 months prior to participation according to self-report.

All subjects in this study also participated in our previous study with metyrapone (Neylan et al, 2003).

\section{Sleep Recording}

Ambulatory polysomnography (Oxford MR95 digital recorder) was used to monitor two nights of sleep. Subjects adhered to a stable sleep-wake schedule at their habitual times. The first night of polysomnography was used as an adaptation night and was not utilized in the analyses. The parameters recorded included an electroencephalogram (EEG) at leads C3 and C4, right and left electrooculograms (EOG), submental electromyogram (EMG), and an electrocardiogram (EKG) in accordance with standardized guidelines. An oximeter (Respironics Cricket) was used to screen for obstructive sleep apnea (OSA). The cutoff criterion for apnea was 10 desaturation events per hour in bed, which has been shown to have a sensitivity of $98 \%$ and a specificity of $48 \%$ in detecting OSA (Series et al, 1993). Subjects who screened positive for OSA were excluded. All sleep was imported into Pass Plus (Delta Software) analytic software and visually scored in 30-s epochs (Rechtschaffen and Kales, 1968). Delta sleep activity was analyzed by period amplitude analysis (PAA) using the Pass Plus (Delta Software) analytic software. Integrated amplitude of 0.3$4.0 \mathrm{~Hz}$ activity per $30 \mathrm{~s}$ epoch was analyzed by NREM cycles on all epochs of NREM sleep across the night following the technique described by Feinberg et al $(1987,1991)$ and (Travis et al, 1991). Epochs scored as wake were not included in these analyses. Movement artifact was visually monitored and recorded and not included in the analyses.

\section{Neuroendocrine Measures}

A 24-h urinary collection was obtained on the second day of sleep recordings for integrated measures of cortisol and creatinine release. Samples were immediately frozen after 
the collection and were analyzed at the General Clinical Research Center's endocrine core lab at the Brigham \& Women's hospital in Boston, MA. Urinary cortisol was measured using a competitive binding immunoenzymatic assay. Urinary creatinine was measured in parallel to control for adequate sampling. Only samples with creatinine values within the normal range $(0.8-2.0 \mathrm{~g} / 24 \mathrm{~h})$ were used. Results are expressed as $24-\mathrm{h} \mu \mathrm{g}$ cortisol and as $24-\mathrm{h} \mu \mathrm{g}$ cortisol/g creatinine.

Subjects self-administered the low-dose $(0.5 \mathrm{mg})$ salivary dexamethasone suppression either at least 1 week before or after the sleep recordings in their home environment to ensure that dexamethasone does not interfere with sleep measures. Subjects were instructed to maintain a stable sleep-wake schedule during the dexamethasone suppression test, to perform this procedure in the middle of their working week, to awaken at the same clock time on the preand post-dexamethasone saliva collection days, and to abstain from activities such as brushing or flossing their teeth, smoking, exercising, and ingesting food or drink prior to or during the collection. On day 1, salivary cortisol was collected $1 \mathrm{~h}$ after wake time and dexamethasone was given $15 \mathrm{~h}$ after wake time. The following morning, salivary cortisol was collected again $1 \mathrm{~h}$ after wake time. Samples were collected at home using Salivettes (Sarstedt Inc, Newton, NC), returned by mail, and deep-frozen $\left(-78^{\circ} \mathrm{C}\right)$ until assay. We relied on the subjects to inform us about the time of sampling. As dexamethasone bioavailability may affect cortisol levels (O’Sullivan et al, 1997), we measured dexamethasone levels for covariance analysis and to check compliance with the protocol. Salivary cortisol and dexamethasone were assayed using radioimmunoassay as previously described (Goenjian et al, 1996).

\section{Statistical Analyses}

Differences in demographic characteristics between PTSD subjects and controls were compared using $t$-tests for continuous variables and $\chi^{2}$ tests for dichotomous variables. Mean 24-h urinary cortisol concentration and salivary cortisol suppression after dexamethasone was compared between groups with univariate ANOVA. The effect of dexamethasone on cortisol was also analyzed by a repeatedmeasures ANCOVA with condition (dexamethasone) as a within-subjects factor and group membership as a betweensubjects factor covarying for dexamethasone levels. The relationships among measures of PTSD and depression, sleep and HPA activity were analyzed by two-tailed Pearson correlations. All values are expressed as mean and standard deviation. As a nominal level of significance, $\alpha=0.05$ was accepted.

\section{RESULTS}

There were no significant differences between PTSD subjects and controls regarding age, body mass index (BMI), smoking, urinary creatinine, urinary volume, and salivary dexamethasone concentrations (Tables 1 and 2). As expected, participants with PTSD had higher scores on CAPS, IES-R, BDI, and a higher rate of current and lifetime depression (Table 2).
Table I Demographic and Psychometric Data in PTSD Subjects and Healthy Controls

\begin{tabular}{lccc}
\hline & PTSD (n=20) & Controls $(\mathbf{n}=\mathbf{1 7})$ & p-value \\
\hline Demographics & & & \\
Age & $49(7)$ & $48(10)$ & 0.66 \\
BMI & $27(5)$ & $25(3)$ & 0.13 \\
Smokers & & 1 & 0.19 \\
& 5 & & \\
Psychopathology & & $2(<1)$ & $<0.001$ \\
CAPS & $65(18)$ & $2(3)$ & $<0.001$ \\
IES-R & $20(11)$ & $4(5)$ & $<0.001$ \\
BDI & $12(7)$ & 0 & 0.04 \\
Current depression & 4 & 0 & $<0.001$ \\
Lifetime depression & 14 & & \\
\hline
\end{tabular}

Data are mean $(\mathrm{SD})$ unless otherwise indicated. $\mathrm{BMI}=$ Body Mass Index; CAPS = Clinician Administered PTSD Scale; IES-R = Impact of Event ScaleRevised; $\mathrm{BDI}=$ Beck Depression Inventory.

${ }^{\mathrm{a} N u m b e r .}$

\section{4-h Urinary Cortisol}

Of the 36 participants, six subjects (three PTSD subjects, three controls) had a creatinine value outside the normal range $(0.8-2 \mathrm{~g} / 24 \mathrm{~h})$, suggesting either an incomplete collection or overcollection (creatinine values outside the normal range varied between $0.5 \mathrm{~g} / 24 \mathrm{~h}$ and $2.5 \mathrm{~g} / 24 \mathrm{~h}$ ). These subjects were excluded for the analyses.

Mean 24-h urinary cortisol did not differ significantly between groups (Table 2). PTSD subjects had greater 24-h urinary cortisol/g creatinine compared with controls (Table 2 and Figure 1). There was a strong correlation between 24-h urinary cortisol/g creatinine and 24-h urinary cortisol $(r=0.83, p<0.001)$. PTSD subjects with and without current depression did not differ in either 24-h urinary cortisol/g creatinine or 24-h urinary cortisol. Repeating the analyses without smokers did not change the results.

\section{Low-Dose (0.5 mg) Salivary Dexamethasone Suppression Test}

Three control subjects did not return their samples of the dexamethasone test. We excluded two participants (one PTSD subject, one control) who showed an implausible and strong increase of their cortisol values after dexamethasone, suggesting a possible collection error, for example, contamination of the saliva with food. The values for cortisol suppression after dexamethasone for these subjects were more than $3 \mathrm{SD}$ below the mean cortisol suppression of the sample. Thus, 19 PTSD subjects and 12 controls were included in the analyses of the dexamethasone test.

In a repeated-measure ANOVA for log-transformed salivary cortisol values, there was neither a main effect for group $(\mathrm{F}=2.5, p=0.12)$ nor a group $\times$ condition interaction $(\mathrm{F}=2.2, p=0.15)$. As expected, there was a strong effect of condition (dexamethasone) on cortisol $(\mathrm{F}=162.8$, $p<0.001$ ). Adding dexamethasone concentration as a 
Table 2 Endocrine and Sleep Data in PTSD Subjects and Controls

\begin{tabular}{|c|c|c|c|c|}
\hline & PTSD $(N=20)^{a}$ & Controls $(N=16)^{b}$ & Effect size ${ }^{c}$ & $p$-value \\
\hline \multicolumn{5}{|l|}{ Neuroendocrinology } \\
\hline $24 \mathrm{~h}$ cortisol $(\mu \mathrm{g})$ & $52(15)$ & $43(23)$ & 0.47 & 0.19 \\
\hline $24 \mathrm{~h}$ cortisol/creatinine $(\mu \mathrm{g} / \mathrm{g})$ & $40(17)$ & $28(12)$ & 0.80 & $0.03^{\mathrm{a}}$ \\
\hline Urinary creatinine $(g / 24 h)$ & $1.4(0.4)$ & $1.4(0.4)$ & 0 & 0.52 \\
\hline Urinary volume (1/24h) & $2.0(0.9)$ & $1.8(0.8)$ & 0.23 & 0.43 \\
\hline \% Cortisol suppression & $73(18)$ & $83(10)$ & 0.65 & 0.06 \\
\hline Dexamethasone concentration & $37(35)$ & $61(62)$ & 0.51 & 0.18 \\
\hline \multicolumn{5}{|l|}{ Sleep } \\
\hline
\end{tabular}

Data are mean (SD). DEX = dexamethasone.

aPTSD: $n=17$ for urinary cortisol, $n=19$ for dexamethasone test.

bControls: $n=14$ for urinary cortisol, $n=12$ for dexamethasone test.

'Effect size expressed as Cohen's d.

${ }^{d}$ No significant main effect for group $(F=2.5, p=0.12)$ nor a group $\times$ time interaction $(F=2.2, p=0.15)$ in a repeated-measures ANOVA.

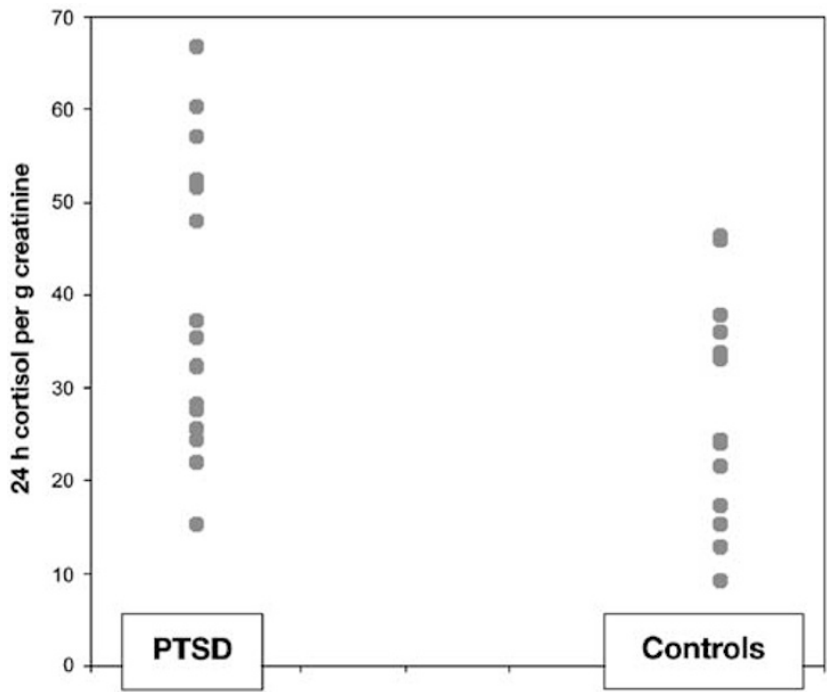

Figure I Individual 24-h urinary cortisol/creatinine values in participants with PTSD $(n=20)$ and matched healthy controls $(n=16)$. Values are expressed as urinary secretion of $\mu \mathrm{g}$ cortisol/g creatinine over $24 \mathrm{~h}$.

covariate in the analyses or using raw values did not change the results. However, there was a trend for less salivary cortisol suppression after dexamethasone in PTSD subjects compared with controls (Table 2 and Figure 2). There were no differences in pre-DEX cortisol levels (Table 2). Again, PTSD patients with and without current depression did not differ in their post-dexamethasone cortisol levels or percent suppression (both $p$-values $>0.50$ ). Also, repeating the analyses without smokers did not change the results.

\section{Delta Sleep}

PTSD subjects spent fewer minutes in delta sleep than controls and had smaller percentage of delta sleep (Table 2). These results have been presented and are described in greater detail elsewhere (Neylan et al, 2003).

\section{Association between Delta Sleep and HPA Axis}

In the combined sample of PTSD and control subjects, time spent in delta sleep was significantly and negatively correlated with 24-h urinary cortisol $(r=-0.36, p=0.04)$ and with 24-h urinary cortisol/g creatinine on a trend level $(r=-0.34, p=0.06)$. We also examined the correlation between 24-h urinary cortisol and measures of delta sleep separately in both groups. The magnitude of the negative correlations between 24 -h urinary cortisol and time spent in delta sleep did not differ between groups (PTSD subjects $r=-0.26$, controls $r=-0.33, p=0.83$ ). If analyzed separately for each group, these correlations between urinary cortisol and delta sleep were not significant, presumably related to the decrease in statistical power.

\section{DISCUSSION}

We confirmed our first hypothesis, finding higher levels of 24-h urinary cortisol associated with less delta sleep. Contrary to our hypotheses, we found increased 24-h urinary cortisol/g creatinine in subjects with PTSD. We did not observe a significant main effect for group or a group $\times$ time interaction in the dexamethasone suppression test. However, PTSD subjects had a trend for less rather than more cortisol suppression after dexamethasone. 

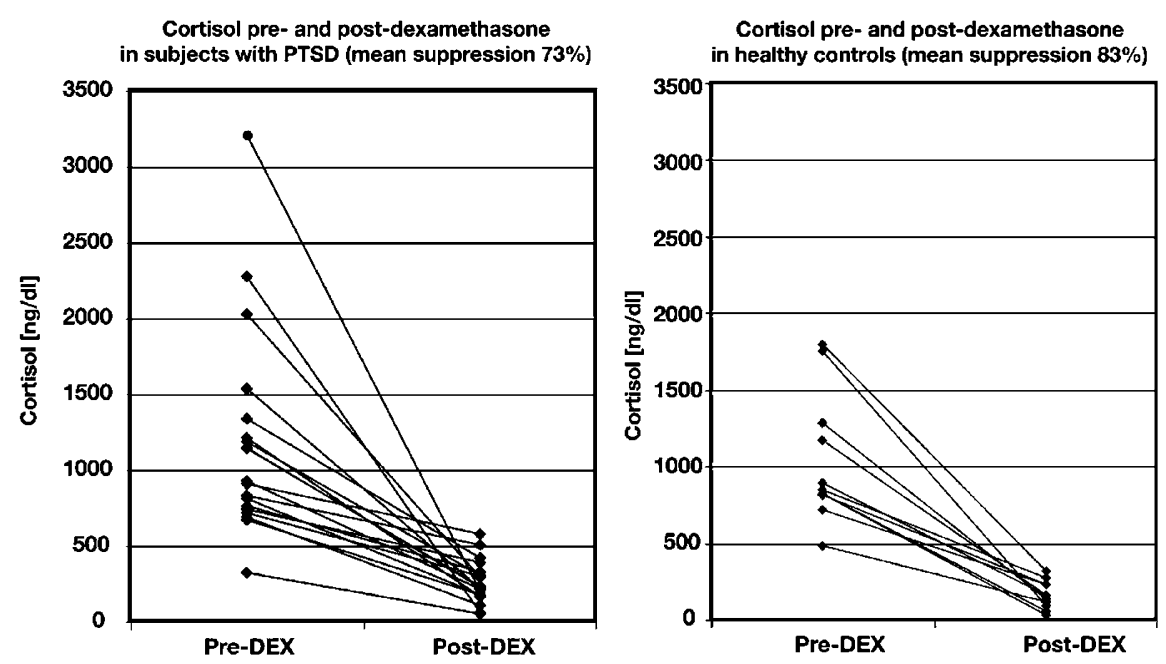

Figure 2 Individual salivary cortisol values before and after $0.5 \mathrm{mg}$ dexamethasone in participants with PTSD $(n=19)$ and matched healthy controls $(n=12)$. Saliva samples were taken I $\mathrm{h}$ after wakening on the first day for pre-DEX cortisol values. Dexamethasone $(0.5 \mathrm{mg})$ was administered I $5 \mathrm{~h}$ after wakening on the first day and I h after wakening on the second day. Saliva was collected to determine post-DEX cortisol values.

The negative relation between 24 -h urinary cortisol and delta sleep that we found in our sample is likely to be driven by hypothalamic CRF. The evidence supporting the role of increased hypothalamic CRF being associated with decreased delta sleep includes the following: (1) hypercortisolemic depression is associated with increased hypothalamic CRF and decreased delta sleep (Steiger, 2002), (2) there is a strong inverse relationship between delta sleep and pulsatile cortisol release (Born and Fehm, 1998; Vgontzas et al, 1999), (3) exogenous cortisol infusion, which reduces $\mathrm{CRF}$ in the hypothalamus, increases delta sleep (Bohlhalter et al, 1997; Friess et al, 2004, 1994), (4) metyrapone administration, which leads to an increase in hypothalamic CRF, causes a decrease in delta sleep (Jahn et al, 2003; Neylan et al, 2003), and (5) rats with genetically reduced hypothalamic CRF spent more time in delta sleep than genetically intact rats (Opp, 1997).

The mechanism by which CRF might decrease delta sleep is not known. One candidate explanation is that an increase in hypothalamic CRF release affects other brain areas involved in sleep or arousal. This possibility is supported by studies showing that not only extrahypothalamic CRF neurons but also neurons from the hypothalamus (AstonJones et al, 1986; Valentino et al, 1992) project to the locus ceruleus, which may be a point of integration between neurohormonal and neurotransmitter CRF systems (Koob, 1999). It is possible that stimulation of the locus ceruleus by way of CRF neurons from the hypothalamus is of sufficient magnitude to affect delta sleep. However, other constituents that parallel cortisol release from the adrenal gland, such as dehydroepiandrosterone (DHEA), could be involved in sleep regulation. Consistent with this hypothesis, DHEA has recently been associated with sleep disturbances and symptom load in PTSD (Rasmusson et al, 2004; Sondergaard et al, 2002).

Our findings of less delta sleep, greater 24-h urinary cortisol/g creatinine, and a trend for less cortisol suppression after dexamethasone are consistent with increased hypothalamic CRF release in PTSD subjects compared with controls. Two studies have found higher levels of CRF in the cerebrospinal fluid in PTSD (Baker et al, 1999; Bremner et al, 1997). In our previous study, subjects with PTSD had a diminished ACTH response to an indirect CRF challenge with metyrapone, also suggesting increased CRF activity in PTSD subjects at baseline (Neylan et al, 2003).

However, findings regarding the HPA axis have been mixed in PTSD (for reviews, see Rasmusson et al, 2003; Yehuda, 2002). Our sample of PTSD patients showed rather increased HPA activity and decreased delta sleep (see also Neylan et al, 2003). We cannot rule out the possibility that there are biological subgroups of PTSD and that, perhaps for a variety of random factors, we selected a subgroup with worse sleep disturbance and increased HPA activity. Similarly, in depression altered HPA axis activity is found in only about $50-60 \%$ of patients (Wolkowitz et al, 2001). In our study, comorbid depression cannot explain the results because PTSD patients with and without depression did not differ on any HPA measure. It is also possible that the focus on middle-aged male subjects who were free from psychotropic medication and comorbid substance abuse, who were recruited to a study focused on sleep disturbances, may explain how our results differ from earlier studies.

In our study, the magnitude of the effect size of group on urinary cortisol differed depending on whether cortisol was expressed as 24-h urinary cortisol or 24-h urinary cortisol/g creatinine (Table 2). In theory, these estimates should produce nearly identical estimates in a complete $24 \mathrm{~h}$ collection, and they did not raise the possibility of random errors in the collection of the urine samples. However, urinary volume and creatinine were not significantly different between groups. Our data support the possibility that urinary cortisol methodology may not provide the most accurate assessment of hormonal release due to subjects' problems in adhering to the protocol, as has been previously suggested (Yehuda et al, 2003). The findings also suggest that observations about the relationship between cortisol and sleep should be confirmed using a more comprehensive methodology such as 24 -h plasma cortisol circadian rhythm analysis. 
Previous studies have used the salivary low-dose dexamethasone test in traumatized adults and adolescents, but some of them did not specifically examine PTSD (Goenjian et al, 1996; Heim et al, 1998; Kellner et al, 1997). Further, these studies either had no control group (Goenjian et al, 1996; Kellner et al, 1997) or no healthy control group (Heim et al, 1998). Our results are in agreement with recent studies in adolescents (Lipschitz et al, 2003) and adults (Lindley et al, 2004), which also failed to find an enhanced negative feedback inhibition in PTSD in a low-dose salivary dexamethasone test. Interestingly, in our study, dexamethasone concentrations were somewhat lower in patients compared with healthy controls (Table 2). This might have contributed to our results and could indicate higher cortisol in patients over time, since dexamethasone half-life is shortened with increasing cortisol levels, presumably due to induction of metabolizing enzymes (Holsboer et al, 1986; Stokes et al, 2002). However, it should be noted that other studies found increased cortisol suppression in PTSD subjects using the low-dose dexamethasone suppression test in plasma (Stein et al, 1997; Yehuda et al, 1993).

Several limitations must be kept in mind when appraising our findings. First of all, we only found increased cortisol in PTSD when relating it to urinary creatinine output and only a trend for less cortisol suppression, indicating rather subtle HPA alterations. Although we made every effort to ensure adequate collection of saliva and urine samples, we relied on participants' self-report in terms of adhering to the protocol. Our small sample size might have reduced our power to detect significant differences in all HPA measures. In fact, we would have needed 72 subjects in each group to have $80 \%$ power on a significance level of 0.05 to detect a significant between-group difference of the effect size we found for 24-h urinary cortisol. In addition, we would have needed 32 subjects in each group to find a significant group difference in percent cortisol suppression after dexamethasone. Further, we examined only men and therefore we do not know if our results are generalizable to women. Finally, we do not have direct evidence that increased CRF is responsible for the HPA findings, decreased delta sleep, or symptoms of PTSD and depression. Once a CRF antagonist becomes available in humans, these hypotheses should be further tested.

In summary, we found decreased delta sleep, increased 24-h urinary cortisol/g creatinine, and a trend for less cortisol suppression after dexamethasone in patients with PTSD. Greater 24-h urinary cortisol/g creatinine was associated with less delta sleep. Future longitudinal studies should focus on cause and effect relationships among psychopathology, HPA alterations, and sleep disturbances in PTSD.

\section{ACKNOWLEDGEMENTS}

We thank Melissa Maglione and Nicholas Rosenlicht for excellent technical assistance. This work was supported by the National Institutes of Health (TCN: MH057157), the General Clinical Research Center, Moffitt Hospital, University of California, San Francisco, with funds provided by the National Center for Research Resources, 5 M01 RR00079, US Public Health Service, a Veterans Affairs Merit
Review grant (Yehuda), Sierra Pacific Mental Illness Research, Education, and Clinical Center (MIRECC), and the Deutsche Forschungsgemeinschaft (Otte, Ot 209/2-1).

\section{REFERENCES}

Armitage R, Hoffmann RF (2001). Sleep EEG, depression and gender. Sleep Med Rev 5: 237-246.

Aston-Jones G, Ennis M, Pieribone VA, Nickell WT, Shipley MT (1986). The brain nucleus locus coeruleus: restricted afferent control of a broad efferent network. Science 234: 734-737.

Atmaca M, Kuloglu M, Tezcan E, Onal S, Ustundag B (2002). Neopterin levels and dexamethasone suppression test in posttraumatic stress disorder. Eur Arch Psychiatry Clin Neurosci 252: 161-165.

Baker DG, West SA, Nicholson WE, Ekhator NN, Kasckow JW, Hill KK et al (1999). Serial CSF corticotropin-releasing hormone levels and adrenocortical activity in combat veterans with posttraumatic stress disorder. Am J Psychiatry 156: 585-588.

Beck A, Ward C, Mendelson M, Mock J, Erbaugh J (1961). An inventory for measuring depression. Arch Gen Psychiatry 4: 561-571.

Blake DD, Weathers FW, Nagy LM, Kaloupek DG, Gusman FD, Charney DS et al (1995). The development of a ClinicianAdministered PTSD Scale. J Trauma Stress 8: 75-90.

Bohlhalter S, Murck H, Holsboer F, Steiger A (1997). Cortisol enhances non-REM sleep and growth hormone secretion in elderly subjects. Neurobiol Aging 18: 423-429.

Borbely A, Achermann P (2000). Homeostasis of human sleep and models of sleep regulation. In: Kryger M, Roth T, Dement W (eds). Principles and Practice of Sleep Medicine. W.B. Saunders: Philadelphia. pp 377-390.

Born J, Fehm HL (1998). Hypothalamus-pituitary-adrenal activity during human sleep: a coordinating role for the limbic hippocampal system. Exp Clin Endocrinol Diabetes 106: 153-163.

Bremner JD, Licinio J, Darnell A, Krystal JH, Owens MJ, Southwick SM et al (1997). Elevated CSF corticotropin-releasing factor concentrations in posttraumatic stress disorder. Am J Psychiatry 154: 624-629.

De Bellis MD, Baum AS, Birmaher B, Keshavan MS, Eccard CH, Boring AM et al (1999). A.E. Bennett Research Award. Developmental traumatology. Part I: Biological stress systems. Biol Psychiatry 45: 1259-1270.

Dinan TG, Barry S, Yatham LN, Mobayed M, Brown I (1990). A pilot study of a neuroendocrine test battery in posttraumatic stress disorder. Biol Psychiatry 28: 665-672.

Feinberg I, Floyd TC, March JD (1987). Effects of sleep loss on delta $(0.3-3 \mathrm{~Hz})$ EEG and eye movement density: new observations and hypotheses. Electroencephalogr Clin Neurophysiol 67: 217-221.

Feinberg I, Floyd T, March J (1991). Acute deprivation of the terminal $3.5 \mathrm{~h}$ of sleep does not increase delta $(0-3 \mathrm{~Hz})$ electroencephalograms in recovery sleep. Sleep 14: 316-319.

First M, Spitzer R, Williams JBW, Gibbon M (1996). Structured Clinical Interview for DSM-IV (SCID-I; Patient Version ed.). New York State Psychiatric Institute, Biometrics Research: New York.

Friess E, Tagaya H, Grethe C, Trachsel L, Holsboer F (2004). Acute cortisol administration promotes sleep intensity in man. Neuropsychopharmacology 29: 598-604.

Friess E, V Bardeleben U, Wiedemann K, Lauer CJ, Holsboer F (1994). Effects of pulsatile cortisol infusion on sleep-EEG and nocturnal growth hormone release in healthy men. J Sleep Res 3: 73-79.

Glaubman H, Mikulincer M, Porat A, Wasserman O (1990). Sleep of chronic post-traumatic patients. J Traumatic Stress 3: 255-263. 
Glover DA, Poland RE (2002). Urinary cortisol and catecholamines in mothers of child cancer survivors with and without PTSD. Psychoneuroendocrinology 27: 805-819.

Goenjian AK, Yehuda R, Pynoos RS, Steinberg AM, Tashjian M, Yang RK et al (1996). Basal cortisol, dexamethasone suppression of cortisol, and MHPG in adolescents after the 1988 earthquake in Armenia. Am J Psychiatry 153: 929-934.

Halbreich U, Olympia J, Carson S, Glogowski J, Yeh CM, Axelrod S et al (1989). Hypothalamo-pituitary-adrenal activity in endogenously depressed post-traumatic stress disorder patients. Psychoneuroendocrinology 14: 365-370.

Heim C, Ehlert U, Hanker JP, Hellhammer DH (1998). Abuserelated posttraumatic stress disorder and alterations of the hypothalamic-pituitary-adrenal axis in women with chronic pelvic pain. Psychosom Med 60: 309-318.

Held K, Kunzel H, Ising M, Schmid DA, Zobel A, Murck H et al (2004). Treatment with the CRH1-receptor-antagonist R121919 improves sleep-EEG in patients with depression. J Psychiatric Res 38: 129-136.

Heuser IJ, Gotthardt U, Schweiger U, Schmider J, Lammers CH, Dettling $\mathrm{M}$ et al (1994). Age-associated changes of pituitaryadrenocortical hormone regulation in humans: importance of gender. Neurobiol Aging 15: 227-231.

Holsboer F, Wiedemann K, Boll E (1986). Shortened dexamethasone half-life in depressed dexamethasone non-suppressors. Arch Gen Psychiatry 43: 813-815.

Jahn H, Kiefer F, Schick M, Yassouridis A, Steiger A, Kellenr M et al (2003). Sleep endocrine effects of the 11-beta-hydroxysteroiddehydrogenase inhibitor metyrapone. Sleep 26: 823-829.

Kellner M, Baker DG, Yehuda R (1997). Salivary cortisol in Operation Desert Storm returnees. Biol Psychiatry 42: 849-850.

Koob GF (1999). Corticotropin-releasing factor, norepinephrine, and stress. Biol Psychiatry 46: 1167-1180.

Kramer M, Kinney L (1988). Sleep patterns in trauma victims with disturbed dreaming. Psychiatr J Univ Ott 13: 12-16.

Lemieux AM, Coe CL (1995). Abuse-related posttraumatic stress disorder: evidence for chronic neuroendocrine activation in women. Psychosom Med 57: 105-115.

Lindley SE, Carlson EB, Benoit M (2004). Basal and dexamethasone suppressed salivary cortisol concentrations in a community sample of patients with posttraumatic stress disorder. Biol Psychiatry 55: 940-945.

Lipschitz DS, Rasmusson AM, Yehuda R, Wang S, Anyan W, Gueoguieva $\mathrm{R}$ et al (2003). Salivary cortisol responses to dexamethasone in adolescents with posttraumatic stress disorder. J Am Acad Child Adolesc Psychiatry 42: 1310-1317.

Maes M, Lin A, Bonaccorso S, van Hunsel F, Van Gastel A, Delmeire L et al (1998). Increased 24-h urinary cortisol excretion in patients with post-traumatic stress disorder and patients with major depression, but not in patients with fibromyalgia. Acta Psychiatr Scand 98: 328-335.

Mellman TA, David D, Kulick-Bell R, Hebding J, Nolan B (1995a). Sleep disturbance and its relationship to psychiatric morbidity after Hurricane Andrew. Am J Psychiatry 152: 1659-1663.

Mellman TA, Kulick-Bell R, Ashlock LE, Nolan B (1995b). Sleep events among veterans with combat-related posttraumatic stress disorder. Am J Psychiatry 152: 110-115.

Mellman TA, Kumar A, Kulick-Bell R, Kumar M, Nolan B (1995c). Nocturnal/daytime urine noradrenergic measures and sleep in combat-related PTSD. Biol Psychiatry 38: 174-179.

Mellman TA, Nolan B, Hebding J, Kulick-Bell R, Dominguez R (1997). A polysomnographic comparison of veterans with combat-related PTSD, depressed men, and non-ill controls. Sleep 20: 46-51.

Neylan TC, Lenoci M, Maglione ML, Rosenlicht NZ, Metzler TJ, Otte C et al (2003). Delta sleep response to metyrapone in post-traumatic stress disorder. Neuropsychopharmacology 28: $1666-1676$.
Neylan TC, Marmar CR, Metzler TJ, Weiss DS, Zatzick DF, Delucchi KL et al (1998). Sleep disturbances in the Vietnam generation: findings from a nationally representative sample of male Vietnam veterans. Am J Psychiatry 155: 929-933.

Opp M (1997). Rat strain differences suggest a role for corticotropin-releasing hormone in modulating sleep. Physiol Behav 63: 67-74.

O'Sullivan BT, Cutler DJ, Hunt GE, Walters C, Johnson GF, Caterson ID (1997). Pharmacokinetics of dexamethasone and its relationship to dexamethasone suppression test outcome in depressed patients and healthy control subjects. Biol Psychiatry 41: $574-584$.

Otte C, Hart S, Neylan T, Yaffe K, Marmar C, Mohr D (2005). A meta-analyis of cortisol response in human aging: importance of gender. Psychoneuroendocrinology 30: 80-91.

Pillar G, Malhotra A, Lavie P (2000). Post-traumatic stress disorder and sleep — what a nightmare!. Sleep Med Rev 4: 183-200.

Pitman RK, Orr SP (1990). Twenty-four hour urinary cortisol and catecholamine excretion in combat-related posttraumatic stress disorder. Biol Psychiatry 27: 245-247.

Rasmusson A, Vasek J, Lipschitz D, Vojvoda D, Mustone M, Shi Q et al (2004). An increased capacity for adrenal DHEA release is associated with decreased avoidance and negative mood symptoms in women with PTSD. Neuropsychopharmacology 29: 1546-1557.

Rasmusson A, Vythilingam M, Morgan C (2003). The neuroendocrinology of posttraumatic stress disorder: new directions. CNS Spectrum 8: 651-667.

Rasmusson AM, Lipschitz DS, Wang S, Hu S, Vojvoda D, Bremner JD et al (2001). Increased pituitary and adrenal reactivity in premenopausal women with posttraumatic stress disorder. Biol Psychiatry 50: 965-977.

Rechtschaffen A, Kales A (1968). A Manual of Standardized Terminology, Techniques and Scoring System for Sleep Stages of Human Subjects. US Dept. of Health Education and Welfare: Bethesda.

Ross RJ, Ball WA, Dinges DF, Kribbs NB, Morrison AR, Silver SM et al (1994a). Motor dysfunction during sleep in posttraumatic stress disorder. Sleep 17: 723-732.

Ross RJ, Ball WA, Dinges DF, Kribbs NB, Morrison AR, Silver SM et al (1994b). Rapid eye movement sleep disturbance in posttraumatic stress disorder. Biol Psychiatry 35: 195-202.

Seeman TE, Singer B, Charpentier P (1995). Gender differences in patterns of HPA axis response to challenge: Macarthur studies of successful aging. Psychoneuroendocrinology 20: 711-725.

Series F, Marc I, Cormier Y, La Forge J (1993). Utility of nocturnal home oximetry for case finding in patients with suspected sleep apnea hypopnea syndrome. Ann Intern Med 119: 449-453.

Sondergaard H, Hansson L, Theorell T (2002). Elevated blood levels of dehydroepiandrosterone sulphate vary with symptom load in posttraumatic stress disorder: findings from a longitudinal study of refugees in Sweden. Psychother Psychosom 71: 298-303.

Steiger A (2002). Sleep and the hypothalamo-pituitary-adrenocortical system. Sleep Med Rev 6: 125-138.

Stein MB, Yehuda R, Koverola C, Hanna C (1997). Enhanced dexamethasone suppression of plasma cortisol in adult women traumatized by childhood sexual abuse. Biol Psychiatry 42: $680-686$.

Stokes P, Sikes C, Lasley B, Stoll P (2002). HPA hyperactivity with increased plasma cortisol affects dexamethasone metabolism and DST outcome. J Psychiatr Res 36: 417-421.

Thaller V, Vrkljan M, Hotujac L, Thakore J (1999). The potential role of hypocortisolism in the pathophysiology of PTSD and psoriasis. Coll Antropol 23: 611-619.

Travis F, Maloney T, Means M, March J, Feinberg I (1991). Acute deprivation of the terminal four hours of sleep does not increase 
delta $(0-3-\mathrm{Hz})$ electroencephalograms: a replication. Sleep 14 320-324.

Valentino RJ, Page M, Van Bockstaele E, Aston-Jones G (1992). Corticotropin-releasing factor innervation of the locus coeruleus region: distribution of fibers and sources of input. Neuroscience 48: $689-705$.

Vgontzas AN, Mastorakos G, Bixler EO, Kales A, Gold PW, Chrousos GP (1999). Sleep deprivation effects on the activity of the hypothalamic-pituitary-adrenal and growth axes: potential clinical implications. Clin Endocrinol (Oxf) 51: 205-215.

Weiss D, Marmar C (1996). The impact of event scale-revised. In: Wilson J, Keane T (eds). Assessing Psychological Trauma and PTSD. A Handbook for Practitioners. Guilford Press: New York. pp 399-411.

Wolkowitz OM, Epel ES, Reus VI (2001). Stress hormone-related psychopathology: pathophysiological and treatment implications. World J Biol Psychiatry 2: 115-143.

Woodward SH, Bliwise DL, Friedman MJ, Gusman DF (1996a). Subjective versus objective sleep in Vietnam combat veterans hospitalized for PTSD. J Trauma Stress 9: 137-143.

Woodward SH, Bliwise DL, Friedman MJ, Gusman FD (1996b). First night effects in post-traumatic stress disorder inpatients. Sleep 19: 312-317.

Woodward SH, Friedman MJ, Bliwise DL (1996c). Sleep and depression in combat-related PTSD inpatients. Biol Psychiatry 39: 182-192.

Woodward SH, Murburg MM, Bliwise DL (2000). PTSD-related hyperarousal assessed during sleep. Physiol Behav 70: 197-203.
Yehuda R (2002). Current status of cortisol findings in post-traumatic stress disorder. Psychiatr Clin North Am 25: 341-368, vii.

Yehuda R, Halligan SL, Grossman R, Golier JA, Wong C (2002). The cortisol and glucocorticoid receptor response to low dose dexamethasone administration in aging combat veterans and holocaust survivors with and without posttraumatic stress disorder. Biol Psychiatry 52: 393-403.

Yehuda R, Halligan SL, Yang RK, Guo LS, Makotkine I, Singh B et al (2003). Relationship between 24-hour urinary-free cortisol excretion and salivary cortisol levels sampled from awakening to bedtime in healthy subjects. Life Sci 73: 349-358.

Yehuda R, Kahana B, Binder-Brynes K, Southwick SM, Mason JW, Giller EL (1995). Low urinary cortisol excretion in holocaust survivors with posttraumatic stress disorder. Am J Psychiatry 152: 982-986.

Yehuda R, Southwick SM, Krystal JH, Bremner D, Charney DS, Mason JW (1993). Enhanced suppression of cortisol following dexamethasone administration in posttraumatic stress disorder. Am J Psychiatry 150: 83-86.

Yehuda R, Southwick SM, Nussbaum G, Wahby V, Giller Jr EL, Mason JW (1990). Low urinary cortisol excretion in patients with posttraumatic stress disorder. J Nerv Ment Dis 178: 366-369.

Young EA, Breslau N (2004). Cortisol and catecholamines in posttraumatic stress disorder: an epidemiologic community study. Arch Gen Psychiatry 61: 394-401. 